\title{
Present day bias and future change signal of temperature over China in a series of multi-GCM driven RCM simulations
}

\author{
Jia $\mathrm{Wu}^{1} \cdot$ Xuejie $\mathrm{Gao}^{2,3}$
}

Received: 3 April 2019 / Accepted: 3 November 2019 / Published online: 13 November 2019

(c) The Author(s) 2019

\begin{abstract}
Simulation of surface air temperature over China from a set of regional climate model (RCM) climate change experiments are analyzed with the focus on bias and change signal of the RCM and driving general circulation models (GCMs). The set consists of 4 simulations by the RCM of RegCM4 driven by 4 different GCMs for the period of 1979-2099 under the mid-range RCP4.5 (representative concentration pathway) scenario. Results show that for present day conditions, the RCM provides with more spatial details of the distribution and in general reduces the biases of GCM, in particular in DJF (December-January-February) and over areas with complex topography. Bias patterns show some correlation between the RCM and driving GCM in DJF but not in JJA (June-July-August). In JJA, the biases in RCM simulations show similar pattern and low sensitivity to the driving GCM, which can be attributed to the large effect of internal model physics in the season. For change signals, dominant forcings from the driving GCM are evident in the RCM simulations as shown by the magnitude, large scale spatial distribution, as well as interannual variation of the changes. The added value of RCM projection is characterized by the finer spatial detail in sub-regional (river basins) and local scale. In DJF, profound warming over the Tibetan Plateau is simulated by RCM but not GCMs. In general no clear relationships are found between the model bias and change signal, either for the driving GCMs or nested RCM.
\end{abstract}

Keywords Bias $\cdot$ Change signal $\cdot$ Temperature $\cdot$ Regional climate model $\cdot$ China

\section{Introduction}

At present, general circulation models (GCMs) are the most commonly used tool in climate change simulations and projections. Undoubtedly, they produce useful results on the global scale. However, they tend to exhibit a relatively low performances in describing the present day climate in regional scale due to their coarse resolutions, which may lead to a less reliable projected future changes (e.g. Gao et al. 2001; Giorgi et al. 2001; Zhou and Li 2002; Kang and Yoo 2006; Christensen et al. 2007; Xu et al. 2010; Flato

Xuejie Gao

gaoxuejie@mail.iap.ac.cn

1 National Climate Center, China Meteorological Administration, Beijing, China

2 Climate Change Research Center, Institute of Atmospheric Physics, Chinese Academy of Sciences, Beijing, China

3 Collaborative Innovation Center on Forecast and Evaluation of Meteorological Disasters, Nanjing University of Information Science and Technology, Nanjing, China et al. 2013; Kirtman et al. 2013; Woldemeskel et al. 2015; Jiang et al. 2016; Rummukainen 2016).

Thus, to meet also the increasing demand for fine scale regional and local climate information usable for impact assessment studies, regional climate models (RCMs) with higher horizontal resolution have been widely used nowadays (e.g. Déqué et al. 2005, 2012; Giorgi et al. 2009; Mearns et al. 2013; Niu et al. 2015; Gao and Giorgi 2017). Application of RCMs over East Asia is in particular important due to its complex topography and unique weather and climate systems (Hirakuchi and Giorgi 1995; Gao et al. 2001, 2006; Lee and Hong 2014; Yu et al. 2010, 2015; Zou and Zhou 2013; Niu et al. 2015; Shi et al. 2017). In addition to the finer scale topographically induced structures in the climate change signals, the RCMs may project some significantly different patterns of change over the region (Gao et al. 2008, 2012; Tang et al. 2017).

A thorough assessment of models' biases firstly before they are applied for projections is important (Tebaldi and Knutti 2007; de Elia and Cote 2010; Christensen and Boberg 2013; Flato et al. 2013; Hui et al. 2018). In the meantime, 
as well known, credibility of RCMs depends largely on the quality of the GCMs providing the large-scale boundary conditions (van Oldenborgh et al. 2009; Déqué et al. 2012; Diaconescu and Laprise 2013; Tang et al. 2017; Tamara et al. 2019). Then to what extent the model biases affect the climate change signal, how and to what extent the GCM bias/signal may transfer (inherit) into the nested RCM? Efforts have been devoted in addressing the issues.

Of the first concern within the context of global warming is the change in temperature. Giorgi and Coppola (2010) found that for temperature in the regional scale, essentially no relationship is found between the bias and change signal based on their analysis on multi-GCM simulations. To be more specific, the projected future changes in temperature depend more on climate sensitivity of the models rather than corresponding regional biases as indicated by Giorgi (2008).

Di Luca et al. (2012) analyzed the added value of RCMs over North America. They found that the climate change signals for seasonal temperature were similar to those in the driving GCMs, and the spatial detail gained by downscaling was not large in the regional scale. Boberg and Christensenc (2012) suggested that over Mediterranean, climate models (regional and global) with systematic biases tend to overestimate regional amplification of global warming. Eum et al. (2015) investigated the relationship between climate change signals and biases for RCM/AOGCM simulations to assess the dependence of future projections on regional model biases for extreme temperature over southern Québec (Canada). They found that changes of extreme temperatures could be significantly affected by a large-scale forcing from boundary conditions, rather than systematic biases in the RCMs.

Three RCMs were applied over south-east Australia by Olson et al. (2016). The analysis shows that the RCMs tend to be biased cold than the GCMs during warm seasons. The downscaled projections are broadly consistent with the GCMs but to a weaker warming over land. Sørland et al. (2018) investigated the bias patterns and climate change signals from a set of RCM simulations under the EUROCORDEX (the International COordinated Regional climate Downscaling Experiment, Giorgi et al. 2009) framework (Jacob et al. 2014). They found that the two RCMs systematically reduced the biases and modified climate change signals of the driving GCMs, most noticeably by lowering the warming of the driving GCMs.

Of the limited studies been conducted over East Asia, Gao et al. (2012) compared temperature changes simulated by a RCM and 2 driving GCMs during the monsoon season of May-September. They found that the large-scale boundary forcing from GCMs dominates the warming magnitude and broad patterns of the RCM over the region. Based on multi-RCM simulations driven by one GCM, Tang et al. (2016) reported a less warming projected compared to the
GCM, in particular during the cold seasons. Park et al. (2016) found the systematic RCM biases, such as a cold bias along the coastline and a warm bias in the northern China, are mostly influenced by the GCM forcings. However, a systematic assessment of the bias-change relationship is still insufficient so far over the region, despite the many RCM simulations conducted here.

Recently, a new and unprecedented set of RCM (RegCM4) 21st century climate change experiments have been conducted over East Asia domain. The RCM is driven by 4 different GCMs at a $25 \mathrm{~km}$ grid spacing with the period from 1979 to 2099 under RCP4.5 emission pathway. Based on the simulations, the projected changes in haze pollution potential in China from the air environment carrying capacity perspective (Han et al. 2017), the future climate changes over the Xiong' an District (Wu et al. 2018), and future changes in thermal conditions over China by using the index of effective temperature (Gao et al. 2018), have been previously reported.

The experiments also allow us for a systematic comparison of the present day simulations and biases, and future change signals among the GCMs and RCM, as well as between the nested RCM and driving GCM. In the present study, we focus our analysis on temperature, aim at answering the above questions of how the driving GCM affect the RCM simulations, and what are the agreements and disagreements of them over China and its sub-regions.

The paper is organized as follows. A short description of the model, data and experimental designs are provided in Sect. 2. This is followed by result in Sect. 3. Finally we present the conclusion and discussion in Sect. 4.

\section{Model, data and experimental designs}

The Abdus Salam International Centre for Theoretical Physics (ICTP) RegCM Version 4.4 (http://gforge.ictp.it/ $\mathrm{gf} / \mathrm{project} / \mathrm{reg} \mathrm{cm} /$ ), with further developments and implementation of physical processes carried out from the first version of RegCM4 (Giorgi et al. 2012), is employed in this study. We use the same physical configuration as Gao et al. $(2016,2017)$ for a better performance of the model over the region. To be more specific, the land surface process used is the CLM3.5 (Oleson et al. 2008) and the convection is selected as Emanuel scheme (Giorgi et al. 2012). The other model physics includes radiation package from the NCAR Community Climate Model CCM3 (Kiehl et al. 1998), the non-local formulation of Holtslag et al. (1990) for the planetary boundary layer, and resolvable scale precipitation represented by the SUBEX parameterization (Pal et al. 2000). In addtion, the land cover data is updated following Han et al. (2015) based on the vegetation and vegetation regionalization maps of China instead of the default one in CLM. 
Note the RCM uses same model configuration, including the model physics, treatment of boundary conditions, and buffer zones, etc., for all simulations in the study, except the driving GCMs.

The four CMIP5 GCMs used to drive RegCM4 are CSIRO Mk3.6.0 (Rotstayn et al. 2010), EC-EARTH (Hazeleger et al. 2010), HadGEM2-ES (Collins et al. 2011), and MPI-ESM-MR (Stevens et al. 2012; Jungclaus et al. 2013). They are hereinafter referred to as CSIRO, EC, Had, and MPI, respectively. Horizontal resolutions of their atmospheric component are spectral T63 $\left(1.875^{\circ} \times 1.875^{\circ}\right.$, longitude $\times$ latitude), $\mathrm{T} 159\left(1.125^{\circ}\right)$, N96 $\left(1.875^{\circ} \times 1.25^{\circ}\right)$ and T63, respectively. The models are selected due to their high resolutions to match the $25 \mathrm{~km}$ grid spacing RCM, data availability, and their good performances over the region (Jiang et al. 2016).

Accordingly, the four RCM simulations conducted are referred to as CdR, EdR, HdR and MdR, respectively. The domain (Fig. 1) follows phase II of CORDEX East Asia domain, which cover whole China and the adjacent areas and oceans. The simulations cover the period of 1979-2099, where the period of 1986-2005 is considered as present day, and 2080-2099 as the end of 21st century.

The gridded observational dataset of CN05.1 (Wu and Gao 2013) is applied to validate the simulations, with the resolution of $0.25^{\circ} \times 0.25^{\circ}$. The model outputs are interpolated bilinearly to the CN05.1 grid to facilitate the comparison. The same weighted average is used for the ensemble mean of the four global models and four RegCM4.4 simulations, referred to as ensG and ensR, respectively.

The analysis is focus on DJF and JJA over the China region and its 10 main river basins (MWRC 1981) as shown in Fig. 1, namely Songhuajiang River Basin (SRB), Liaohe Basin (LRB), Haihe Basin (HaiRB), Yellow River Basin (YLB), Huai River Basin (HRB), Yangtze River Basin (YRB), Zhujiang River Basin (ZRB), Southeast Rivers Basin (SERB), Southwest Rivers Basin (SWRB), and interior rivers in the Northwest Basin (NWRB). Definition of the 10 main river basins in general follows the major rivers in eastern China with dense population and more developed economic conditions. For western China, the rivers in southwest entering Southeast or South Asia are generalized as SWRB, while the rivers in northern Tibetan Plateau and northwest China as interior rivers in the NWRB. The definition is officially recommended by The Ministry of Water Resources of China and used widely in the scientific communities (e.g. water resources, hydrological, and climate, etc.). In addition, the river basins also agree roughly with the major climatic zones in China.

\section{Result}

\subsection{Biases in present day simulation}

\subsubsection{Whole of China}

Firstly, we compare the simulated ensemble mean temperature of driving GCMs (ensG) and nested RCM simulations (ensR) over China during DJF and JJA in the present day against observations to validate the models' performances. In DJF over eastern China (Fig. 2a), the observed temperature shows a distinct latitudinal distribution, drops from over $12{ }^{\circ} \mathrm{C}$ in the south to less than $-18{ }^{\circ} \mathrm{C}$ in the Northeast.

(a) Model domain

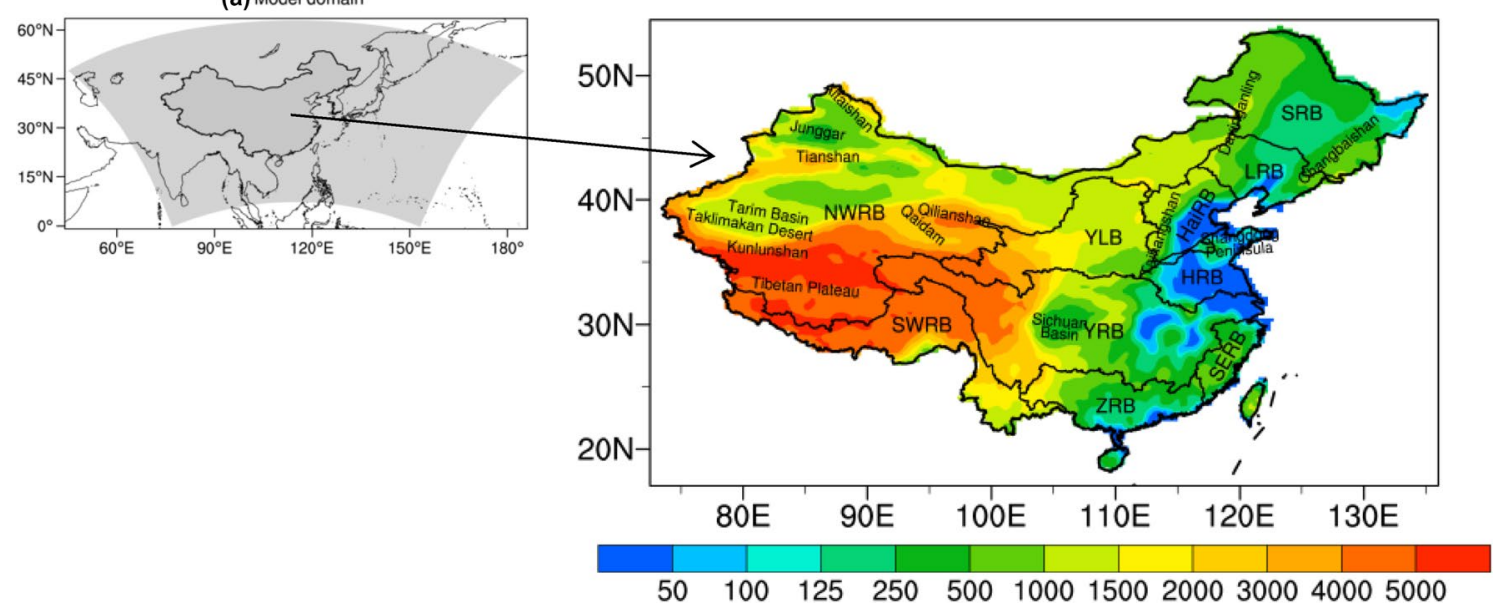

Fig. 1 Model domain (gray shading in a), topography (colored, unit: $\mathrm{m})$, and the 10 river basins over China (b). 1. Songhuajiang River Basin (SRB); 2. Liaohe Basin (LRB); 3. Haihe Basin (HaiRB); 4. Yellow River Basin (YLB); 5. Huai River Basin (HRB); 6. Yangtze
River Basin (YRB); 7. Zhujiang River Basin (ZRB); 8. Southeast Rivers Basin (SERB); 9 Southwest Rivers Basin (SWRB); 10. Interior rivers in the Northwest Basin (NWRB) 

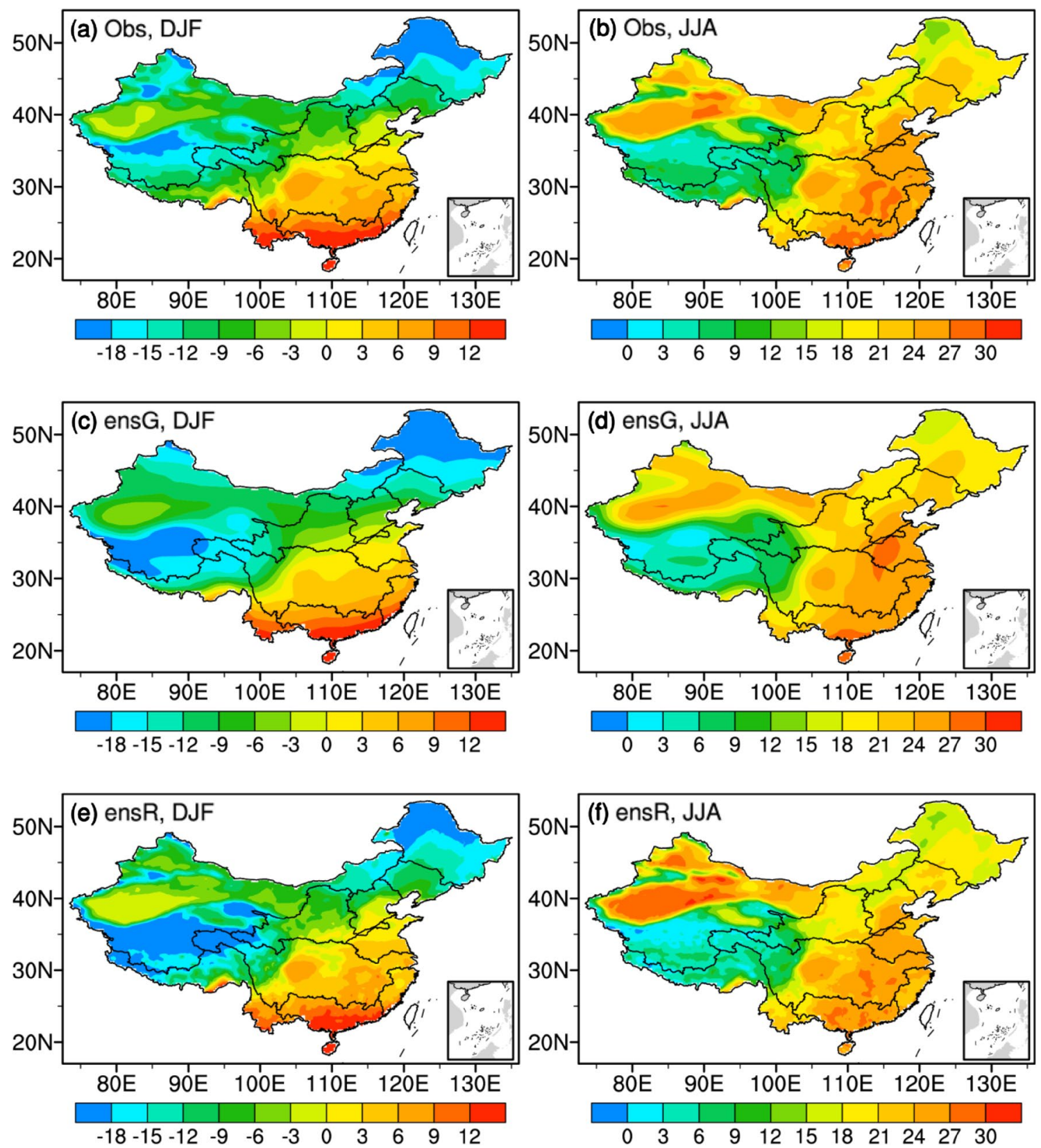

Fig. 2 Mean temperature during 1986-2005 over China (units: ${ }^{\circ} \mathrm{C}$ ): a observation in DJF; b observation in JJA; $\mathbf{c}$ GCM ensemble simulation in DJF; $\mathbf{d}$ GCM ensemble simulation in JJA; $\mathbf{e}$ RCM ensemble simulation in DJF; $\mathbf{f}$ RCM ensemble simulation in JJA

Strong topography dependence is found in western China, with the maximum above $0{ }^{\circ} \mathrm{C}$ in basins and less than $-18{ }^{\circ} \mathrm{C}$ over the mountain peaks. Both ensG (Fig. 2c) and ensR (Fig. 2e) reproduce the spatial pattern well and ensR provides more spatial details following its higher resolution. For example, the relatively lower temperature zone over Tianshan, Qilianshan, and other mountains in the Northwest are well captured in ensR but not in ensG. The seasonal evolution and general pattern of the observed temperatures in JJA (Fig. 2b) are well captured by both ensG (Fig. 2d) and
ensR (Fig. 2f) while ensR shows much finer spatial detail as expected.

Temperature biases (simulation minus observation) of different driving GCMs and nested RCM simulations, as well as their respective ensemble means in DJF are presented in Fig. 3. A prevailing cold bias is found in ensG except over northeastern part of Northeast China and mountain ranges in the Northwest. The largest cold bias, in excess of $7.5^{\circ} \mathrm{C}$, is found in southern part of the Tibet Plateau (Fig. 3a). Despite a dominated warm bias in MPI, 
consistencies in the cold bias are found over the Northeast Plain, Sichuan Basin, and Tibetan Plateau in all the models and ensG (Fig. 3a). Note some of the biases are due to the excessively smoothed topography in the coarse resolution GCMs. For example, the cold biases over plains (Northeast Plain) and basins (e.g. Qaidam Basin in the Northwest and Sichuan Basin in Southwest), and warm biases over mountain ranges (e.g. Qilian, Tianshan, and Kunlun Mountains in the Northwest). In addition, pattern of the bias is also consistent to most other GCMs, with the regional mean value $-1.3^{\circ} \mathrm{C}$ (see Table 2 below) close also to a very large ensemble of the GCMs $\left(-1.1{ }^{\circ} \mathrm{C}\right)$ as reported by Jiang et al. (2016).

Table 1 presents values of the spatial correlation coefficients (CORs) of temperature biases in DJF across the model simulations over China. The CORs between different RCM (GCM) simulations indicate the consistency of model biases in RCM (GCMs) (i.e. to what extent they are similar to each), while the CORs between GCM and nested RCM indicate to what extent the GCMs are forcing the RCM. Following Zwiers and von Storch (1995), statistical significance of the spatial correlation is calculated using the equivalent sample size method as did in Gao et al. (2017).

As shown in the table, although large differences in the values can be found for GCMs' biases (Fig. 3; Table 1), the CORs across them are high, with values in the range of $0.39-0.77$, all statistically significant at $95 \%$ confidence level. As shown in Fig. 3a, high level of agreements are found over plains and basins (cold bias), as well as mountain ranges (warm bias). Thus at least part of the large CORs of GCM biases can be attributed to their coarse resolution to describe the smaller scale topography and consequently the temperatures there.

Regional mean biases of the RCM are less in 3 out of the 4 simulations compared to the corresponding driving GCMs, in the range of -1.3 to $-0.4{ }^{\circ} \mathrm{C}$ (Table 2). The RCM improvement over the small scale topographic complex areas, e.g. mountain ranges and nearby basins in the Northwest, is evident (Fig. 3d, h, f, i). It is of interest to note that although the biases of GCMs show large differences, the biases of nested RCM are in good agreements with each other, either in the magnitude or spatial distribution. This indicates the RCM biases do not always follow the driving GCM. 3 out of 4 CORs between each pair of the GCM/ RCM (except around 0 value for $\mathrm{Had} / \mathrm{HdR}$ ) are statistically significant, indicating the large forcings of GCM during the season when large scale circulation dominants. As shown in Fig. 3b, the common biases of RCM include warm bias in the Northeast and Northwest China, and cold bias in the Tibetan Plateau and SERB, etc. This is also in agreement with previous RegCM simulations (Gao and Giorgi 2017), indicating the internal model processes dominant over the region as interior of this large domain. The CORs across
RCM simulations are thus high with the values range from 0.89 to 0.99 (Table 1 ).

Figure 4 presents temperature biases in JJA for the models and ensemble means. Better performance is found in JJA compared to DJF (Fig. 3), with the biases mostly within $\pm 5{ }^{\circ}$ C. Similar to DJF (Fig. 3a), a common warm bias over the mountain ranges (e.g. Qilian, Tianshan, and Kunlun Mountains in the Northwest, Taihang Mountain in North China), and a cold bias in the foothills of the mountains (more evident in Northwest with steep topographic gradients) and basins (e.g. Qaidam and Sichuan Basins) in the GCMs are found in JJA. CSIRO and Had show a general warm bias over most of region, especially in YLB and $\mathrm{SRB}$ with the values greater than $2.5^{\circ} \mathrm{C}$. Regional mean for them over China are both as $0.7^{\circ} \mathrm{C}$. In the meantime, cold bias dominants in EC and MPI, with the largest cold bias in excess of $-2.5^{\circ} \mathrm{C}$ found in southern part of the Tibet Plateau. Regional mean bias for EC and MPI are $-1.2{ }^{\circ} \mathrm{C}$ and $-0.3{ }^{\circ} \mathrm{C}$, respectively (Table 2). The GCMs show less agreement with the spatial distribution of the biases and lead to a close 0 value for the regional mean of ensG.

As indicated by the cross symbols in Fig. $4 \mathrm{~b}$ for model agreements, biases of RCM show more consistencies among the runs characterized by a cold bias in northern part of China, eastern coast areas, and the Tibetan Plateau, and a large warm bias over the deserts in the Northwest. It is noted that the above biases show agreements with the RCM driven by re-analysis, except a dominant cold bias along the coast region of Yellow Sea. Similar to reported by Park et al. (2016), this is largely due to the prevailing cold SST bias simulated by the GCMs (figure not shown for brevity).

Regional mean biases for RCM are in general $1{ }^{\circ} \mathrm{C}$ lower compared to the driving GCMs with the ensR as $-1.1{ }^{\circ} \mathrm{C}$ (Table 2). It is interest to note that the regional mean differences of bias between RCM and driving GCM show close value $\left(\sim{ }^{\circ} \mathrm{C}\right.$ ) to the RCM when driven by re-analysis (Gao et al. 2017). In the meantime, influence from driving GCM can be also observed. For the warmer ones of CSIRO and Had, CdR and HdR are also warmer compared to EdR and MdR although values are still negative.

The CORs across the GCMs are also high in JJA, in the range of 0.49-0.83 (Table 3). Similar to DJF (see discussions above), this again can be largely attributed to their similar coarse resolutions. As found in Fig. 4b, broad areas with agreement in bias signs exist (marked by cross), indicating similar pattern of bias in the RCM simulations. This leads to the high CORs of RCM with values ranging from 0.79 to 0.96 . CORs between the RCM and driving GCM are low in JJA, with 3 out of the 4 pairs are negative (except EdR and EC). The low CORs indicate a low sensitivity of RCM to the driving GCM (i.e. less forcing received in RCM) in JJA, implying the RCM behavior depends more on its own internal process in this monsoons season characterized by 

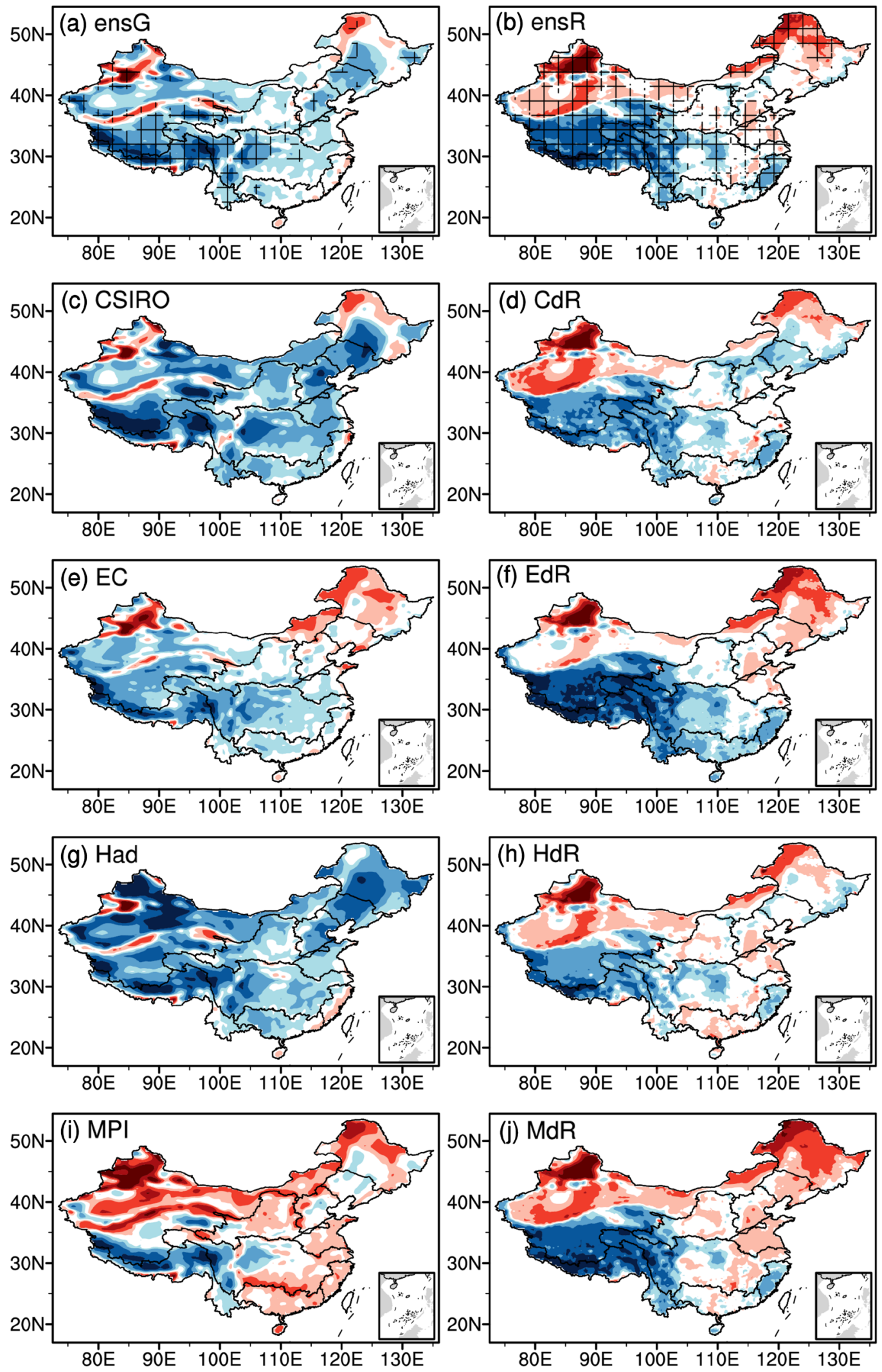

\begin{tabular}{lll|l|l|lll}
-7.5 & -5 & -2.5 & -1 & 1 & 2.5 & 5 & 7.5
\end{tabular} 
4Fig. 3 The biases of mean temperature in DJF during 1986-2005 over China (unit: ${ }^{\circ} \mathrm{C}$ ) between observation and simulations for a ensG; b ensR; c CSIRO; d CdR; e EC; f EdR; g Had; h HdR; i MPI; j MdR. Cross area in $\mathbf{a}$ and $\mathbf{b}$ panels indicates that all simulations simulated the negative/positive bias

smaller scale weather and climate systems. However, similar to DJF, in-depth analysis on the behavior of RCM biases to different driving GCMs is an interesting topic and needs to be explored in the future.

\subsubsection{River basins}

Figure 5 presents the scatter-plots of GCM vs. RCM temperature biases over the 10 major river basins over China in DJF and JJA for a general view of their correlations. The gray shading area in the figure indicates a larger bias of the RCM compared to the driving GCM while the RCM show better performances in the blank areas. In DJF (Fig. 5a), a clear systematic reduction of bias in most basins is found in CdR and HdR, driven by the two GCMs of CSIRO and Had with larger cold bias (Fig. 3; Table 2). The bias of EdR is close to the driving EC over most basins and slightly larger in the rest. HdR shows improvement over a few basins but the biases become larger in the others compared to Had. The RCM is in general cold in JJA which lead to the improvement in CdR and HdR driven by the two warm GCMs of CSIRO and Had (Fig. 5b). In agreement to this, the cold bias in the other two GCMs (EC and MPI) is amplified in EdR and MdR.

The biases of each pair of the GCM/RCM over each of the 10 major river basins in DJF and JJA are presented in Fig. 6 to further show the relationships between the two in the sub-regional scale in China. The correlations show large diversities among the basins in DJF. Strong correlations are mostly found over basins with systematic biases in the RCM. For example in SRB and LRB in the Northeast where a systematic warm bias exists (see Fig. 3b), the RCM tends to simply add a positive value to GCM bias over these subregions thus leads to a good correlation between the GCM and RCM biases. This compensates the cold biases in GCM thus leads to a better simulation by the RCM. Conversely, in SERB with already good performances of GCM, the cold bias of RCM leads to a larger bias of the RCM. It indicates that when the biases of RCM and GCMs are in the reverse/ same direction, the RCM tends to compensates/enlarges the GCM biases, leading to an improved or worsened simulation. However, it is of interest to note that this systematic biases of RCM do not always added directly to the GCM. For example in SRB and LRB, the RCM does not equally warm each GCM. When the GCM itself is already too warm, warming of the RCM tends to be less or nearly zero.
In the meantime over basins where RCM bias is not so systematic, the correlation is in general not significant. Exceptions are found over, e.g. YRB and ZRB, where negative correlations exist. However the differences of the GCM and RCM biases are small there and can be at least partly considered as a random behavior of the model. This further confirms the complex relationships existed between the RCM and driving GCM.

Different from DJF, correlations between RCM and GCM biases are more evident in JJA. With general cold bias of the RCM (see Fig. 4b), it tends to lower the temperatures. In the northern basins in eastern China (SRB, LRB, HaiRB, YLB, HRB and SERB), a kind of shift to the cold direction can be found in the RCM simulations. Again in basins with no systematic bias, the biases of RCM show less correlation with GCM (e.g. in YRB).

\subsection{Change signals in the end of 21 st century}

\subsubsection{Whole of China}

Mean temperature changes in the end of the century (2080-2099) in DJF from the ensemble of GCMs and RCMs, as well as the individual simulations are presented in Fig. 7. Substantial warming is found firstly in all model simulations. For ensemble of GCMs, the warming is in the range of $2.4-3.9^{\circ} \mathrm{C}$ (Fig. 7a), with regional mean as $3.0^{\circ} \mathrm{C}$. The warming is more significant in western China with the largest in excess of $3.6^{\circ} \mathrm{C}$ found over portions in the Northwest and Tibetan Plateau. Differences are large either in the magnitude and spatial distribution from different GCMs (Fig. 7c, $\mathrm{e}, \mathrm{g}, \mathrm{i})$. Regional mean values of the warming over China are the largest for $\mathrm{Had}\left(3.8^{\circ} \mathrm{C}\right)$, followed by $\mathrm{CSIRO}\left(3.4^{\circ} \mathrm{C}\right)$, MPI $\left(2.6^{\circ} \mathrm{C}\right)$, with the least for EC $\left(2.0^{\circ} \mathrm{C}\right)$ (Table 2$)$. CORs among GCMs range from -0.21 to 0.50 , with only 3 out of the 6 pairs are positive and statistically significant, illustrating the large discrepancies among them (Table 4). While a least warming is projected by CSIRO in the Northeast, MPI simulates a greater warming over there (Fig. 7c, i).

Magnitude of the warming simulated by RCM in general follows but smaller than the driving GCM. Regional mean changes are in the range of $1.8-3.2^{\circ} \mathrm{C}$ with ensemble mean as $2.5^{\circ} \mathrm{C}$ (Table 2), half degree lower than GCM. The largest difference is $-1.8{ }^{\circ} \mathrm{C}$ between MdR and MPI with the least of $-0.1{ }^{\circ} \mathrm{C}$ between EdR and EC. In northern basins, the warm bias of the RCM may lead to less snow coverage and consequently a weaker snow-albedo feedback, and finnally a weaker warming. However in the warm south, the mechanism behind is much more complex and need to be further explored in future studies.

The broad pattern of warming in RCM in general agrees well with the driving GCM as shown in Fig. 7. CORs between RCM and the driving GCM are in the range of 
Table 1 Spatial correlation coefficients (CORs) of temperature biases in DJF across the model simulations over China (see Sect. 2 of the main text for definitions of the abbreviations)

\begin{tabular}{ccccccccc}
\hline & CSIRO & EC & Had & MPI & CdR & EdR & HdR & MdR \\
\hline CSIRO & - & $0.59^{*}$ & $0.61^{*}$ & $0.77^{*}$ & $0.31^{*}$ & $0.31^{*}$ & $0.34^{*}$ & $0.33^{*}$ \\
EC & $0.59^{*}$ & - & $0.39^{*}$ & $0.74^{*}$ & $0.51^{*}$ & $0.68^{*}$ & $0.62^{*}$ & $0.65^{*}$ \\
Had & $0.61^{*}$ & $0.39^{*}$ & - & $0.44^{*}$ & -0.11 & -0.06 & -0.03 & -0.05 \\
MPI & $0.77^{*}$ & $0.74^{*}$ & $0.44^{*}$ & - & $0.53^{*}$ & $0.57^{*}$ & $0.59^{*}$ & $0.60^{*}$ \\
CdR & $0.31^{*}$ & $0.51^{*}$ & -0.11 & $0.53^{*}$ & - & $0.89^{*}$ & $0.93^{*}$ & $0.92^{*}$ \\
EdR & $0.31^{*}$ & $0.68^{*}$ & -0.06 & $0.57^{*}$ & $0.89^{*}$ & - & $0.92^{*}$ & $0.99^{*}$ \\
HdR & $0.34^{*}$ & $0.62^{*}$ & -0.03 & $0.59^{*}$ & $0.93^{*}$ & $0.92^{*}$ & - & $0.93^{*}$ \\
MdR & $0.33^{*}$ & $0.65^{*}$ & -0.05 & $0.60^{*}$ & $0.92^{*}$ & $0.99^{*}$ & $0.93^{*}$ & - \\
\hline
\end{tabular}

The asterisks indicate statistically significant at the $95 \%$ confidence level (values $>0.18$ ). Light grey indicates CORs among the GCMs, dark grey for each GCM-RCM pair, and light grey in Italic for CORs among the RCM simulations

Table 2 Regional mean temperature bias (model simulation minus observation) during 1986-2005 and the change during 2080-2099 (relative to 1986-2005) in DJF and JJA for GCM/RCM and (RCM minus GCM) over China (unit: ${ }^{\circ} \mathrm{C}$ )

\begin{tabular}{llllll}
\hline & CSIRO/CdR & EC/EdR & Had/HdR & MPI/MdR & ensG/ensR \\
\hline Bias & & & & & \\
DJF & $-2.6 /-1.2(1.3)$ & $-0.8 /-1.3(-0.5)$ & $-2.6 /-0.4(2.2)$ & $0.7 /-0.4(-1.1)$ & $-1.3 /-0.8(0.5)$ \\
JJA & $0.7 /-0.3(-1.0)$ & $-1.2 /-2.0(-0.8)$ & $0.7 /-0.5(-1.2)$ & $-0.3 /-1.5(-1.2)$ & $-0.0 /-1.1(-1.1)$ \\
Change & & & & & \\
DJF & $3.4 / 3.0(-0.4)$ & $2.0 / 1.9(-0.1)$ & $3.8 / 3.2(-0.6)$ & $2.6 / 1.8(-1.8)$ & $3.0 / 2.5(-0.5)$ \\
JJA & $3.3 / 2.4(-0.9)$ & $1.9 / 1.8(0.1)$ & $3.1 / 3.0(-0.1)$ & $2.3 / 2.3(0.0)$ & $2.7 / 2.4(-0.3)$ \\
\hline
\end{tabular}

0.43-0.64, all significant at 95\% level (Table 4). However, besides more spatial details in RCM, noticeable differences are found over the Tibetan Plateau where a dominant warming exists in 3 out of the 4 simulations except EdR. But still greater warming can be observed in eastern part of the Plateau in EdR. The profound warming in RCM may be related to a stronger feedback effect of warming and reduction in surface albedo due to melting of snow cover (Giorgi et al. 1997). However, further analysis in the future is needed to identify clearly the reasons of the different model responses.

In JJA (Fig. 8), the warming is also profound in all model simulations, but in general weaker and show different patterns compared to DJF. For ensG, the warming is in general greater than $2.4^{\circ} \mathrm{C}$ over the country with the largest value in excess of $3{ }^{\circ} \mathrm{C}$ located in North China and western part of the Northwest (Fig. 8a). Regional mean of the warming is greater for $\mathrm{CSIRO}\left(3.3^{\circ} \mathrm{C}\right)$ and $\operatorname{Had}\left(3.1^{\circ} \mathrm{C}\right)$, and lesser for MPI $\left(2.3^{\circ} \mathrm{C}\right)$ and $\mathrm{EC}\left(1.9^{\circ} \mathrm{C}\right)$, with ensG as $2.7^{\circ} \mathrm{C}$ (Table 2). Similar to DJF, spatial distribution among the GCMs show large differences with only 2 CORs out of the total 6 are positively significant (Table 5 ).

Magnitude of the regional mean warming in JJA from RCM is close to but slightly lower than the driving GCM, except a larger difference of $0.9{ }^{\circ} \mathrm{C}$ for $\mathrm{CSIRO}$ and $\mathrm{CdR}$ (Table 2). The later contributes largely to the $0.3{ }^{\circ} \mathrm{C}$ lower value of ensR. A greater warming $\left(2.4-3.0^{\circ} \mathrm{C}\right)$ is found along $40^{\circ} \mathrm{N}$ and over eastern part of the Tibetan Plateau in ensR (Fig. 8b). As in DJF, the spatial pattern of RCM is consistent with the driving GCM in a broad scale. CORs for the pairs are all significant and range from 0.25 to 0.67 . It is of interesting to note that although the RCM is not so responsive to biases of GCMs (Table 3), it responses the climate change signal of GCMs well, either for the regional mean value or the broad scale spatial distribution of the changes.

In the meantime, as shown in Fig. $8 \mathrm{~d}, \mathrm{f}, \mathrm{h} \mathrm{j}$, spatial patterns across the RCM simulations are not so consistent as in DJF. For CORs among RCM simulations, only 3 out of 6 are positive and significant (Table 5).

\subsubsection{River basins}

Concerning the sub-regions, correlations of the change signal from GCM-RCM pairs over the 10 river basins in the end of century in DJF and JJA are firstly summarized in Fig. 9. A symbol below the dashed line indicates the warming in RCM is weaker, and vice visa. As shown in the figure, differences of the warming between GCM/RCM are in general larger in DJF compared to JJA. In DJF, 3 out of the 4 RCM simulations except EC/EdR, while in JJA only CSIRO/CdR show weaker warming over most basins. Larger spread is found in DJF, either across the simulations or among the basins. The weakening of warming in 

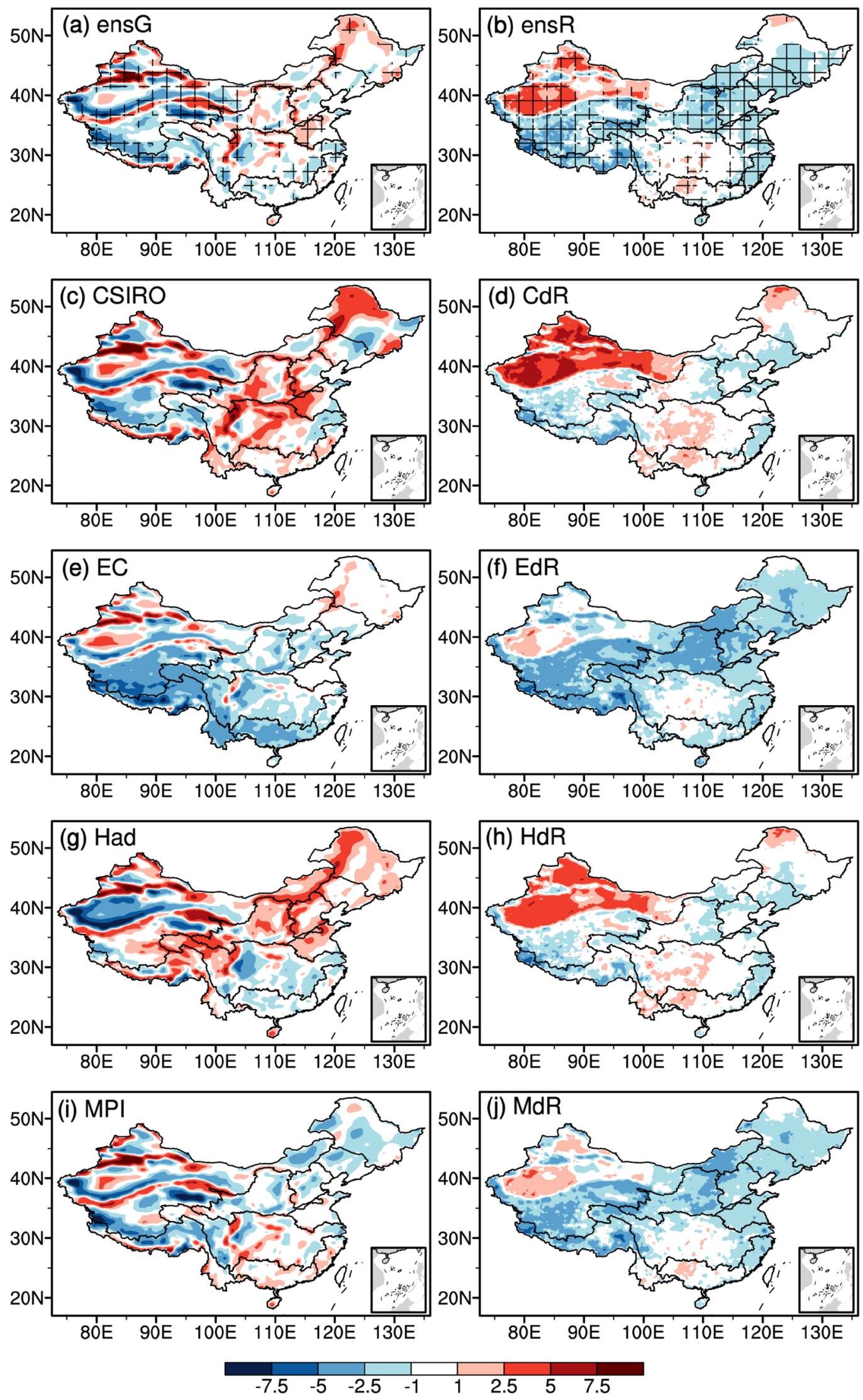

Fig. 4 Same as Fig. 3, but for JJA 
Table 3 Same as Table 1, but for JJA

\begin{tabular}{ccccccccc}
\hline & CSIRO & EC & Had & MPI & CdR & EdR & HdR & MdR \\
\hline CSIRO & - & $0.63^{*}$ & $0.70^{*}$ & $0.83^{*}$ & -0.14 & -0.06 & -0.07 & -0.05 \\
EC & $0.63^{*}$ & - & $0.49^{*}$ & $0.66^{*}$ & 0.17 & $0.18^{*}$ & $0.20^{*}$ & 0.14 \\
Had & $0.70^{*}$ & $0.49^{*}$ & - & $0.68^{*}$ & $-0.44^{*}$ & $-0.42^{*}$ & $-0.34^{*}$ & $-0.41^{*}$ \\
MPI & $0.83^{*}$ & $0.66^{*}$ & $0.68^{*}$ & - & -0.09 & -0.03 & -0.03 & -0.00 \\
CdR & -0.14 & 0.17 & $-0.44^{*}$ & -0.09 & - & $0.79^{*}$ & $0.95^{*}$ & $0.84^{*}$ \\
EdR & -0.06 & $0.18^{*}$ & $-0.42^{*}$ & -0.03 & $0.79^{*}$ & - & $0.85^{*}$ & $0.96^{*}$ \\
HdR & -0.07 & $0.20^{*}$ & $-0.34^{*}$ & -0.03 & $0.95^{*}$ & $0.85^{*}$ & - & $0.91^{*}$ \\
MdR & -0.05 & 0.14 & $-0.41^{*}$ & -0.00 & $0.84^{*}$ & $0.96^{*}$ & $0.91^{*}$ & - \\
\hline
\end{tabular}

The asterisks indicate statistically significant at the $95 \%$ confidence level (values $>0.18$ ). Light grey indicates CORs among the GCMs, dark grey for each GCM-RCM pair, and light grey in Italic for CORs among the RCM simulations
Fig. 5 Comparison of the GCM and RCM biases in DJF (a) and JJA (b) over the 10 major river basins in China during 1986-2005 (unit: ${ }^{\circ} \mathrm{C}$ ). The colored symbols indicate the different pairs of the runs. The numbers indicate different river basins as Fig. 1
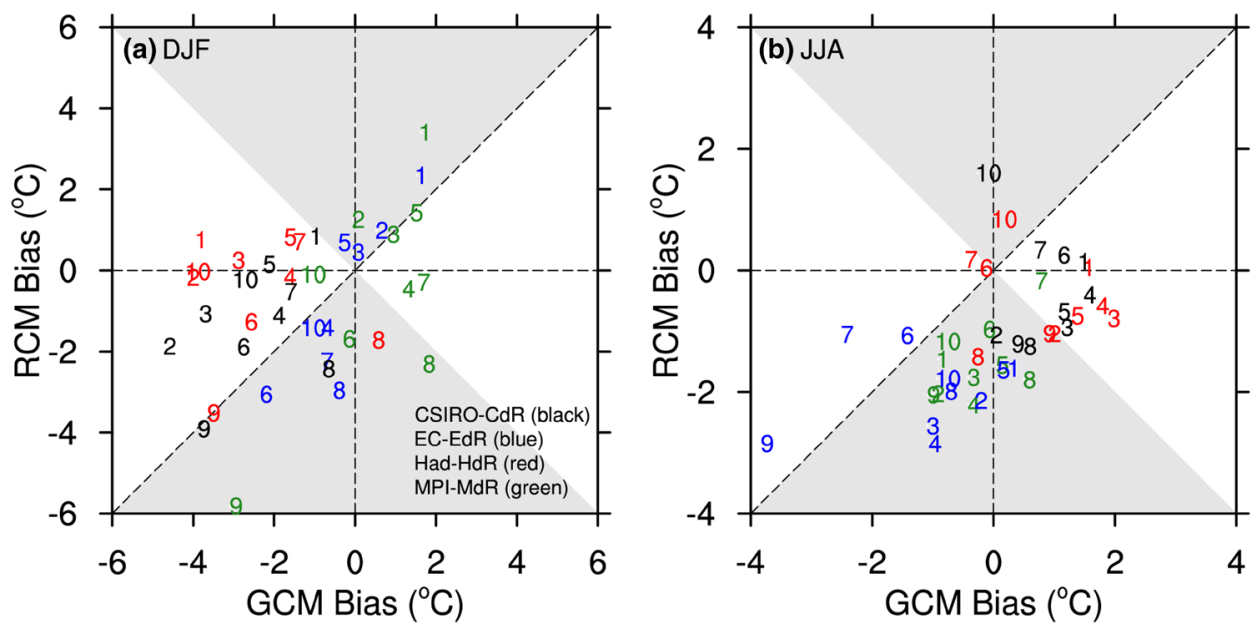

RCM show differences in seasons, sub-regions, as well as driving GCMs. Warming in CSIRO/CdR and $\mathrm{Had} / \mathrm{HdR}$ are more pronounced than the other two over most basins in both DJF and JJA.

As a quantitative measure of consistencies, spatial CORs for each pair of the simulation in the end of century in both DJF and JJA over the river basins are calculated and presented in Table 6. CORs over the whole of China are all positively significant as shown in Tables 4 and 5, indicating the large forcing of GCM in the regional scale. However correlations in the sub-regional scale show large diverse either over different basins or across model pairs. For example in DJF, number of the positive and significant COR (NoSP) for $\mathrm{EC} / \mathrm{EdR}$ is 9, but is 6 only for Had/HdR out of the 10 basins. NoSP is 3 in SRB out of the 4 model pairs, but as 2 for LRB. The correlations in JJA show similar diverse although to a less extent. In addition, the behavior can be very different from DJF over the basins. For instance, a large positive COR of 0.86 is found in YLB for EC/EdR in DJF, but in JJA the COR turns to be a large negative one as -0.61 .
NoSPs for ensG and ensR for DJF and JJA over the basins are 6 and 8, respectively, in the end of the century (Table 7). However as shown in Table 7 , the CORs show also large inter-decadal differences. Over HRB, the COR is close to zero in the end of the century, but is positively significant in the early and mid of the century. In JJA, 8 out of the 10 basins show significant correlations in early and end of the century, but the number is only 4 in the mid-century. In general, correlation exists in around $2 / 3$ circumstances (over different basins or periods) between the RCM and driving GCM.

\subsection{Temporal evolution}

Temporal evolution of temperature changes over China during 2006-2099 in DJF and JJA are presented in Fig. 10. As shown in the figure, a greater warming in DJF compared to JJA can be observed throughout the century. The warming projected in different simulations are almost linear before the mid-21st century and then tend to stabilize following the emission stabilization of RCP4.5 

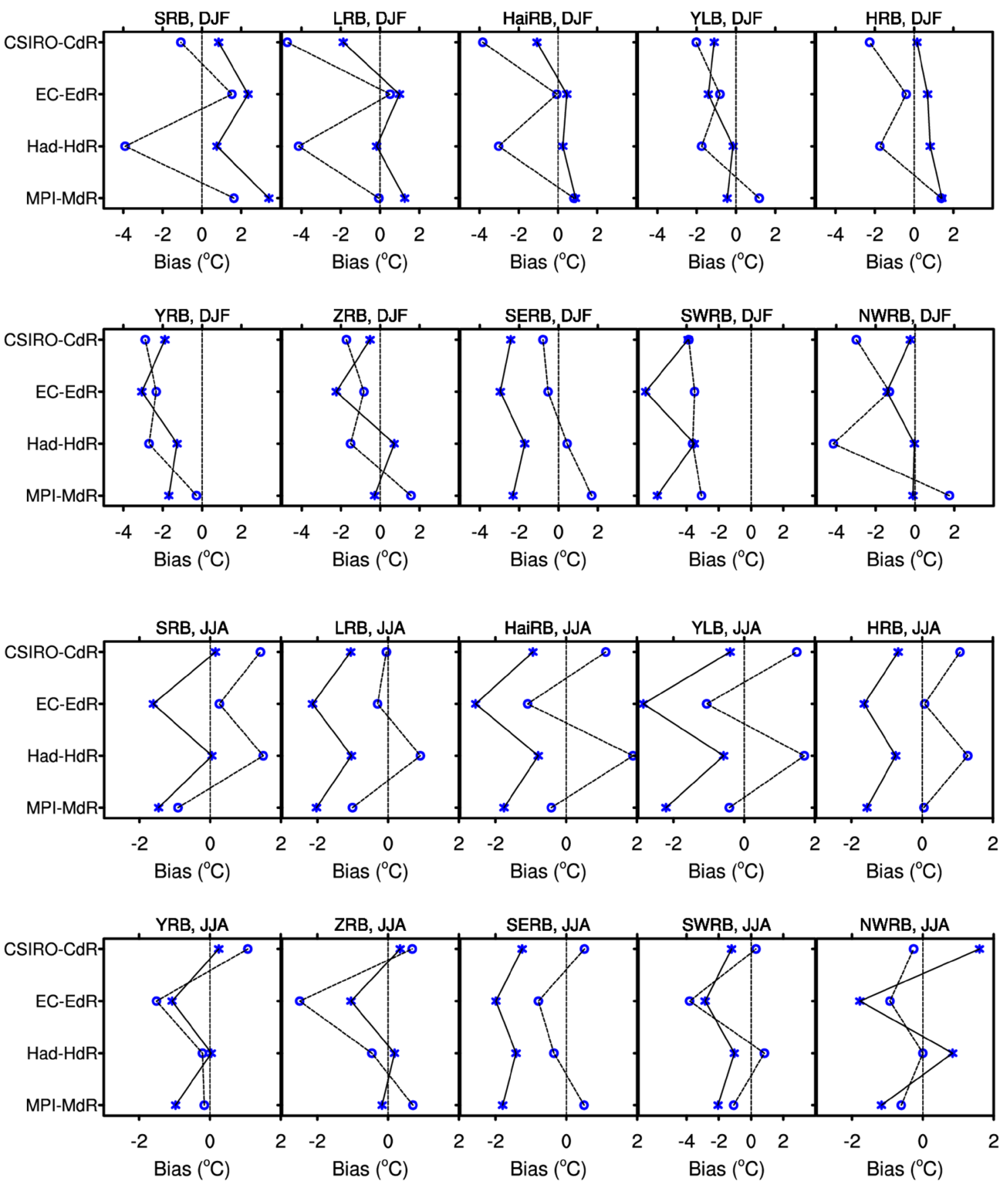

Fig. 6 Biases of each pair of the GCM-RCM over each of the 10 major river basins in China in DJF and JJA during 1986-2005 (unit: ${ }^{\circ} \mathrm{C}$ ). The blue circles and asterisks indicate the biases of GCMs and RCMs, respectively. Note the lines connecting the models do not refer to any continuity between them pathway, in particular for JJA. Spread among the simulations is also less before $\sim 2040$. Similar to the end of the century, the weaker warming in RCM compared to driving GCM is also evident in other periods of the century.
It is noted that the year to year changes of nested RCM follows driving GCM well. The detrended CORs for all model pairs and over all basins in both DJF and JJA are statistically significant (not shown for brevity). Thus the inter-annual variability in the nested RCM is dominated by the driving GCM. 

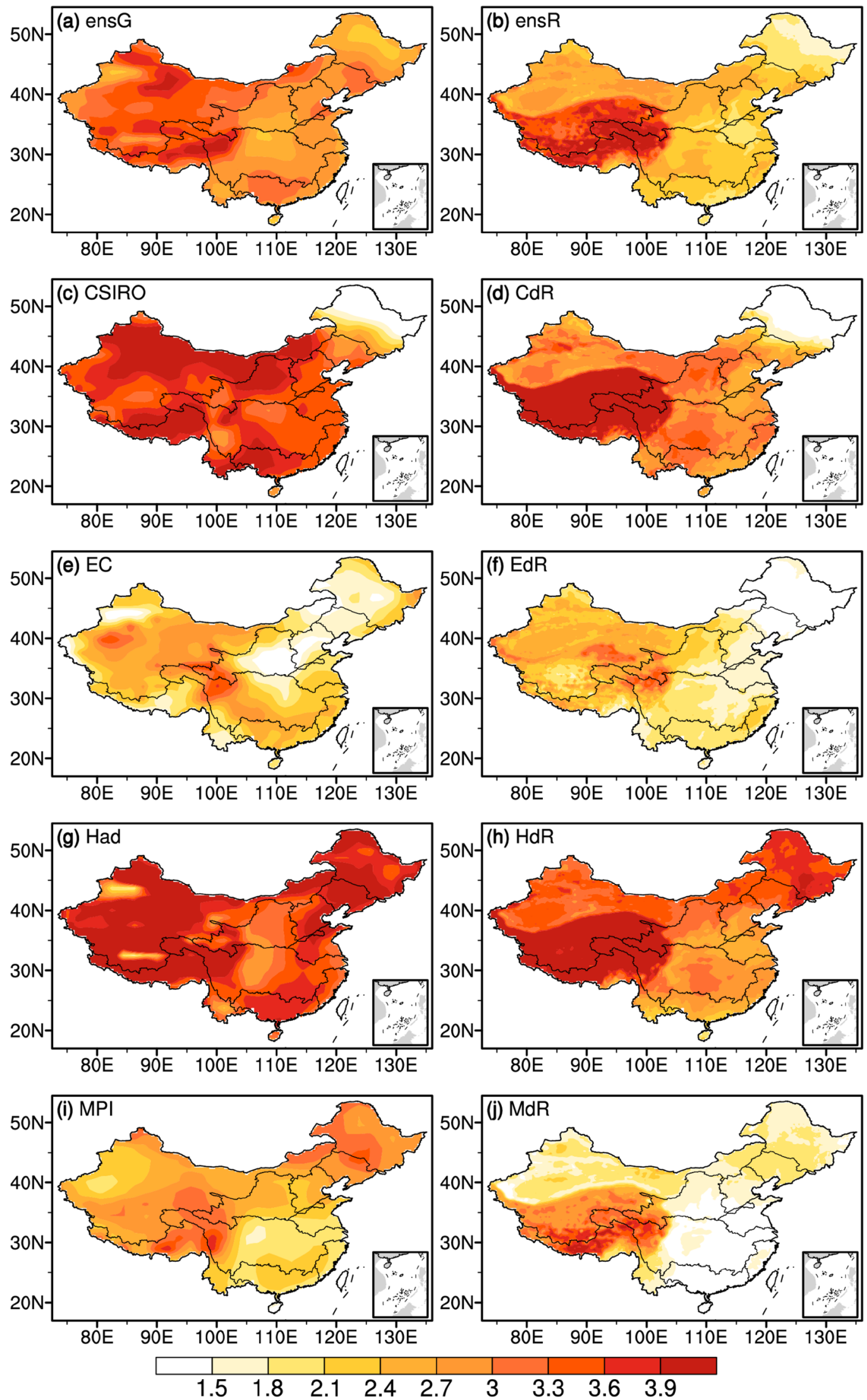

Fig. 7 Simulated changes of mean temperature (unit: ${ }^{\circ} \mathrm{C}$ ) in DJF by a ensG; b ensR; c CSIRO; $\mathbf{d}$ CdR; e EC; f EdR; $\mathbf{g}$ Had; h HdR; i MPI; $\mathbf{j}$ MdR over China during 2080-2099 (relative to 1986-2005) 
Table 4 Same as Table 1 but for temperature changes during 2080-2099 (relative to 1986-2005)

\begin{tabular}{ccccccccc}
\hline & CSIRO & EC & Had & MPI & CdR & EdR & HdR & MdR \\
\hline CSIRO & - & $0.26^{*}$ & 0.12 & $-0.21^{*}$ & $0.64^{*}$ & $0.61^{*}$ & -0.01 & $0.18^{*}$ \\
EC & $0.26^{*}$ & - & $0.24^{*}$ & 0.05 & $0.42^{*}$ & $0.60^{*}$ & $0.35^{*}$ & $0.33^{*}$ \\
Had & 0.12 & $0.24^{*}$ & - & $0.50^{*}$ & $0.23^{*}$ & $0.21^{*}$ & $0.43^{*}$ & $0.51^{*}$ \\
MPI & $-0.21^{*}$ & 0.05 & $0.50^{*}$ & - & 0.12 & 0.04 & $0.70^{*}$ & $0.63^{*}$ \\
CdR & $0.64^{*}$ & $0.42^{*}$ & $0.23^{*}$ & 0.12 & - & $0.74^{*}$ & $0.57^{*}$ & $0.71^{*}$ \\
EdR & $0.61^{*}$ & $0.60^{*}$ & $0.21^{*}$ & 0.04 & $0.74^{*}$ & - & $0.48^{*}$ & $0.53^{*}$ \\
HdR & -0.01 & $0.35^{*}$ & $0.43^{*}$ & $0.70^{*}$ & $0.57^{*}$ & $0.48^{*}$ & - & $0.90^{*}$ \\
MdR & $0.18^{*}$ & $0.33^{*}$ & $0.51^{*}$ & $0.63^{*}$ & $0.71^{*}$ & $0.53^{*}$ & $0.90^{*}$ & - \\
\hline
\end{tabular}

The asterisks indicate statistically significant at the $95 \%$ confidence level (values $>0.18$ ). Light grey indicates CORs among the GCMs, dark grey for each GCM-RCM pair, and light grey in Italic for CORs among the RCM simulations

\section{Conclusion and discussion}

In the present paper, we report analysis on temperature simulations from a set of 4 RCM 21 st century climate change experiments over China. The biases in the present day simulation and change signal in the future projection are presented and inter-compared with the driving GCM, with the focus on the seasons of DJF and JJA.

For present day simulation, the GCMs reproduce well the climatology, while the RCM provides with more spatial detail of the distributions. Biases of the GCMs or RCM show consistencies among themselves, both in spatial distribution and magnitude in the two seasons. The biases of RCM in DJF, at least to some extent, are transferred from the driving GCM. In JJA, internal physics of the RCM may play a larger role, with almost no correlations found for bias distributions between the RCM and driving GCM. Furthermore, the RCM tends to add its systematic biases which lead to a larger bias in its ensemble compared to GCM. The improvement of RCM is more significant in DJF, with the largest added value as a better description of temperature over places with complex terrains.

Concerning future changes, the pattern and magnitude show large differences across the GCMs. It is difficult to conclude a correlation between the GCM bias and change signal. The two models with greatest warming both in DJF and JJA, CSIRO and Had, are the ones with largest climate sensitivity among the 4 (Myhre et al. 2013; Chen and Gao 2019). This further confirms previous findings that regional temperature change signal depends much more on the GCM sensitivity rather than local processes (e.g. Giorgi 2008; Giorgi and Coppola 2010).

The magnitudes and broad regional scale distribution of the warming in RCM in general follows the driving GCMs, indicating dominance of the warming pattern from GCM as reported by Gao et al. (2012). Thus similar to GCM, almost no relationship has been found between the RCM biases and projection. The most significant added value in
$\mathrm{RCM}$ is the much finer spatial detail in sub-regional (river basin) and local scales. The largest difference between RCM projection and GCM is found over the Tibetan Plateau in DJF with a much profound warming in RCM. This leads to the less correlation of the warming patterns between RCM and GCM in the sub-regional scale (the river basins). Furthermore, the correlation varies in the decadal scale.

The change patterns among RCM simulations show good consistencies in DJF when large scale circulation dominates, but not in JJA, the monsoon season with medium and small weather and climate systems prevail.

It is of interest to find that a general reduced warming is projected by the RCM, which is consistent with findings in Australia, Europe, and East Asia (Olson et al. 2016; Tang et al. 2016; Sørland et al. 2018). However, whether this is region or model dependent needs to be further explored. Further analysis is also needed to understand the physical mechanisms behind. For example over Europe, the lowing of warming is significant in JJA, which may relate to the drying feedback over the region (Sørland et al. 2018). However in our simulations, the less warming is more evident in DJF instead, indicating other processes play major roles.

Due to the limited scope of the study, we reported the model behaviors on temperature simulation and projection only in the present paper. In-depth investigation on the physical mechanisms behind requires more special design experiments and need to be conducted in the future. Two sets of experiments are planned so far in the next stage. The first one will be focused on the role of model resolution in projecting future changes, as did by Gao et al. (2006) for present day climatology. In the experiments, resolutions of the RCM will decrease gradually from $25 \mathrm{~km}$ to a coarse resolution comparable to the driving GCM, aiming to identify how the model resolution affects the projected signal. The second set is on model physics. Simulations will be conducted using different convection parameterization schemes, e.g. the Tiedtke (Tiedtke, 1989) implemented recently in 

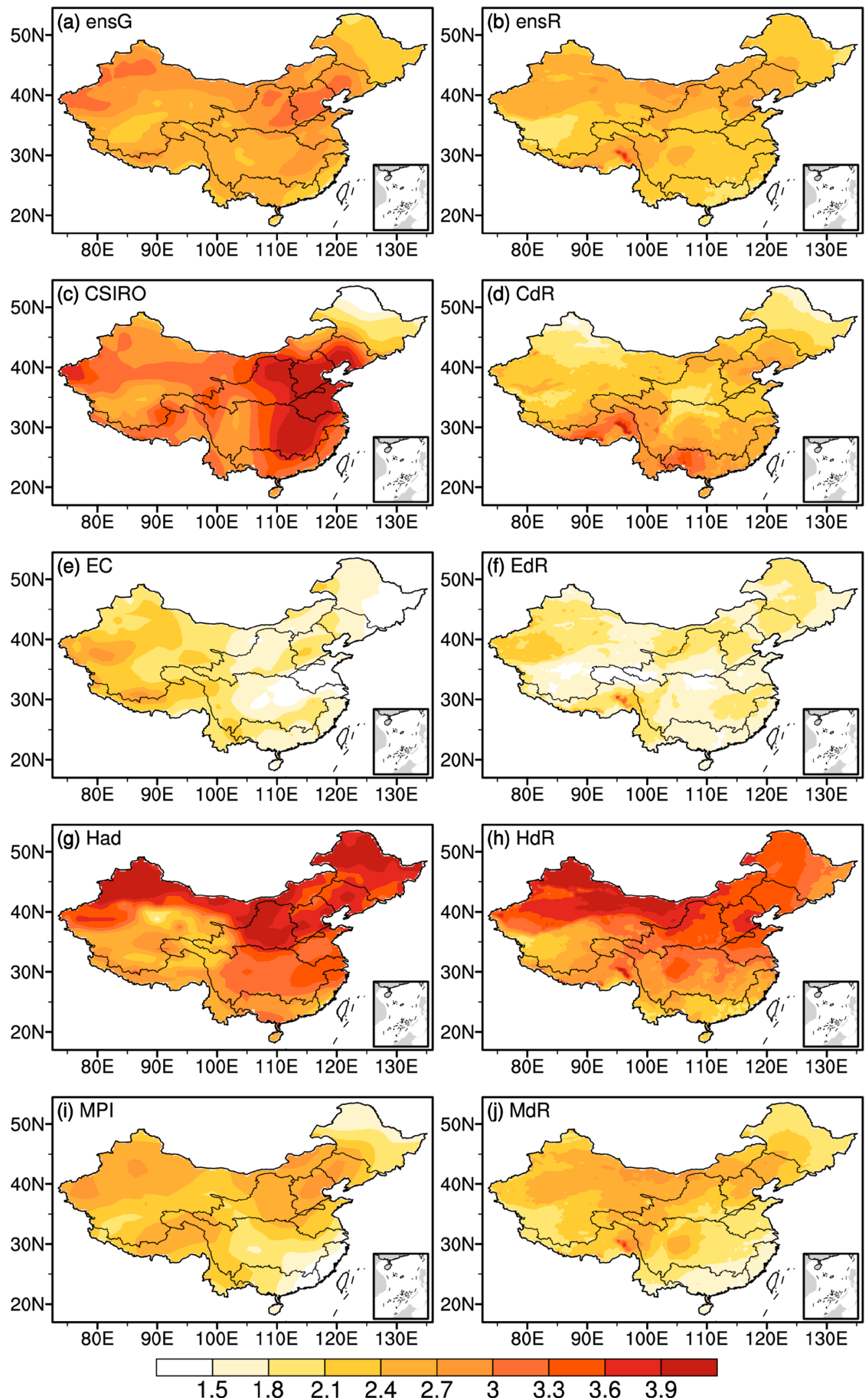

Fig. 8 Same as Fig. 7, but for JJA 
Table 5 Same as Table 4, but for JJA
Fig. 9 Comparison of the GCM and RCM change signals (unit: ${ }^{\circ} \mathrm{C}$ ) in DJF (a) and JJA (b) over the 10 major river basins in China during 20802099 (relative to 1986-2005). The colored symbols indicate the different pairs of the runs. The numbers indicate different river basins as Fig. 1

\begin{tabular}{ccccccccc}
\hline & CSIRO & EC & Had & MPI & CdR & EdR & HdR & MdR \\
\hline CSIRO & - & -0.09 & -0.10 & $0.29^{*}$ & $0.37^{*}$ & -0.02 & 0.01 & 0.05 \\
EC & -0.09 & - & $-0.33^{*}$ & $0.40^{*}$ & 0.13 & $0.25^{*}$ & -0.05 & $0.26^{*}$ \\
Had & -0.10 & $-0.33^{*}$ & - & 0.15 & $-0.53^{*}$ & $0.26^{*}$ & $0.65^{*}$ & 0.15 \\
MPI & $0.29^{*}$ & $0.40^{*}$ & 0.15 & - & -0.04 & $0.26^{*}$ & $0.51^{*}$ & $0.67^{*}$ \\
CdR & $0.37^{*}$ & 0.13 & $-0.53^{*}$ & -0.04 & - & 0.08 & $-0.46^{*}$ & -0.10 \\
EdR & -0.02 & $0.25^{*}$ & $0.26^{*}$ & $0.26^{*}$ & 0.08 & - & $0.36^{*}$ & $0.34^{*}$ \\
HdR & 0.01 & -0.05 & $0.65^{*}$ & $0.51^{*}$ & $-0.46^{*}$ & $0.36^{*}$ & - & $0.69^{*}$ \\
MdR & 0.05 & $0.26^{*}$ & $0.15^{*}$ & $0.67^{*}$ & -0.10 & $0.34^{*}$ & $0.69^{*}$ & - \\
\hline
\end{tabular}

The asterisks indicate statistically significant at the $95 \%$ confidence level (values $>0.18$ ). Light grey indicates CORs among the GCMs, dark grey for each GCM-RCM pair, and light grey in Italic for CORs among the RCM simulations
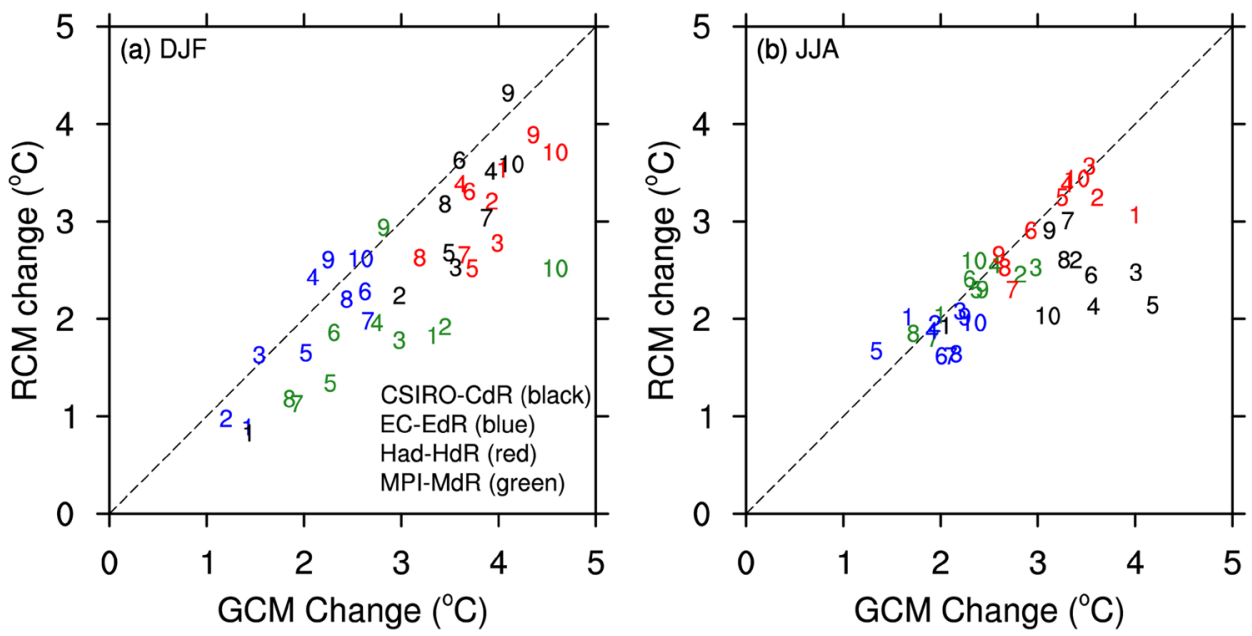

Table 6 Spatial correlation coefficients (CORs) of temperature change between different pair of model simulations in DJF/JJA over the 10 major river basins for 2080 2099 (relative to 1986-2005)

\begin{tabular}{|c|c|c|c|c|c|}
\hline & CSIRO/CdR & EC/EdR & $\mathrm{Had} / \mathrm{HdR}$ & MPI/MdR & NoSP \\
\hline 1-SRB & $0.88 * / 0.86^{*}$ & $0.47 * / 0.05$ & $0.08 / 0.42 *$ & $0.45 * / 0.82 *$ & $3 / 3$ \\
\hline 2-LRB & $0.70 * / 0.82 *$ & $0.44 * / 0.28 *$ & $-0.05 / 0.68^{*}$ & $0.01 / 0.91 *$ & $2 / 4$ \\
\hline 3-HaiRB & $0.67 * / 0.04$ & $-0.06 / 0.54 *$ & $-0.29 * / 0.29 *$ & $0.67 * / 0.83 *$ & $2 / 2$ \\
\hline 4-YLB & $-0.38 * /-0.14$ & $0.81 * /-0.61 *$ & $0.45 * / 0.73 *$ & $0.90 * /-0.27 *$ & $3 / 1$ \\
\hline 5-HRB & $-0.56^{*} /-0.70^{*}$ & $0.33 * / 0.46^{*}$ & $0.23 * / 0.29 *$ & $0.86^{*} / 0.83^{*}$ & $3 / 3$ \\
\hline 6-YRB & $0.37 * /-0.16$ & $0.74 * / 0.12$ & $0.78 * / 0.25 *$ & $0.90 * / 0.58 *$ & $4 / 2$ \\
\hline 7-ZRB & $0.70 * /-0.13$ & $0.31 * / 0.60 *$ & $0.27 * / 0.55^{*}$ & $-0.16 / 0.79 *$ & $3 / 3$ \\
\hline 8-SERB & $0.31 * /-0.54 *$ & $0.90 * / 0.42 *$ & $0.81 * / 0.83 *$ & $-0.14 / 0.58^{*}$ & $3 / 4$ \\
\hline 9-SWRB & $0.48 * / 0.13$ & $0.24 * /-0.16$ & $0.75 * /-0.03$ & $0.74 * / 0.49 *$ & $4 / 1$ \\
\hline 10-NWRB & $-0.39 * / 0.52 *$ & $0.45^{*} / 0.25^{*}$ & $0.02 / 0.71^{*}$ & $0.44 * / 0.24 *$ & $2 / 4$ \\
\hline NoSP & $7 / 5$ & $9 / 6$ & $6 / 9$ & $7 / 9$ & - \\
\hline
\end{tabular}

The asterisks indicate statistically significant at the $95 \%$ confidence level. NoSP indicates number of the river basins with positive and significant COR
RegCM4, to investigate dependence of the change signal on model physics.

As indicated by Gao et al. (2012), precipitation change over the region shows larger uncertainties during the monsoon season. Thus the bias and change analysis will be expanded to precipitation. Finally, climate change simulations conducted over this large domain are still very limited so far compared to other CORDEX regions. Further completion of large multi-GCM/RCM ensembles within the CORDEX framework are needed to better address the issues. 
Table 7 Spatial correlation coefficients (CORs) of temperature change between ensG and ensR in DJF/JJA over China and the 10 major river basins for early (2016-2035) mid (2046-2065) and end of the 21 st century

\begin{tabular}{|c|c|c|c|c|}
\hline & $\begin{array}{l}\text { 2016-2035 } \\
\text { DJF/JJA }\end{array}$ & $\begin{array}{l}\text { 2046-2065 } \\
\text { DJF/JJA }\end{array}$ & $\begin{array}{l}\text { 2080-2099 } \\
\text { DJF/JJA }\end{array}$ & NoSP \\
\hline $\mathrm{CN}$ & $0.66^{*} / 0.56^{*}$ & $0.53 * / 0.56 *$ & $0.68 * / 0.55 *$ & $3 / 3$ \\
\hline 1-SRB & $0.26 * / 0.24 *$ & $0.33 * / 0.50 *$ & $0.63 * / 0.51 *$ & $3 / 3$ \\
\hline 2-LRB & $-0.15 / 0.81^{*}$ & $0.06 / 0.81^{*}$ & $-0.16 / 0.91 *$ & $0 / 3$ \\
\hline 3-HaiRB & $0.47 * / 0.04$ & $0.33 * / 0.24 *$ & $-0.23 * / 0.35^{*}$ & $2 / 2$ \\
\hline 4-YLB & $0.78 * / 0.51 *$ & $0.87 * /-0.49 *$ & $0.83 * / 0.10$ & $3 / 2$ \\
\hline 5-HRB & $0.80 * / 0.53 *$ & $0.39 * /-0.42 *$ & $0.02 / 0.40^{*}$ & $2 / 2$ \\
\hline 6-YRB & $0.90 * / 0.45 *$ & $0.88 * /-0.38 *$ & $0.86 * /-0.34 *$ & $3 / 1$ \\
\hline 7-ZRB & $0.06 / 0.15$ & $0.55 * / 0.62 *$ & $0.56 * / 0.68 *$ & $2 / 2$ \\
\hline 8-SERB & $0.50 * / 0.37 *$ & $0.85 * / 0.11$ & $0.80 * / 0.68 *$ & $3 / 2$ \\
\hline 9-SWRB & $0.77 * / 0.33 *$ & $0.66 * / 0.18^{*}$ & $0.77 * / 0.24 *$ & $3 / 3$ \\
\hline 10-NWRB & $0.32 * / 0.30 *$ & $0.13 / 0.67 *$ & $0.11 / 0.64 *$ & $1 / 3$ \\
\hline NoSP & $8 / 8$ & $8 / 4$ & $6 / 8$ & - \\
\hline
\end{tabular}

The asterisks indicate statistically significant at the $95 \%$ confidence level
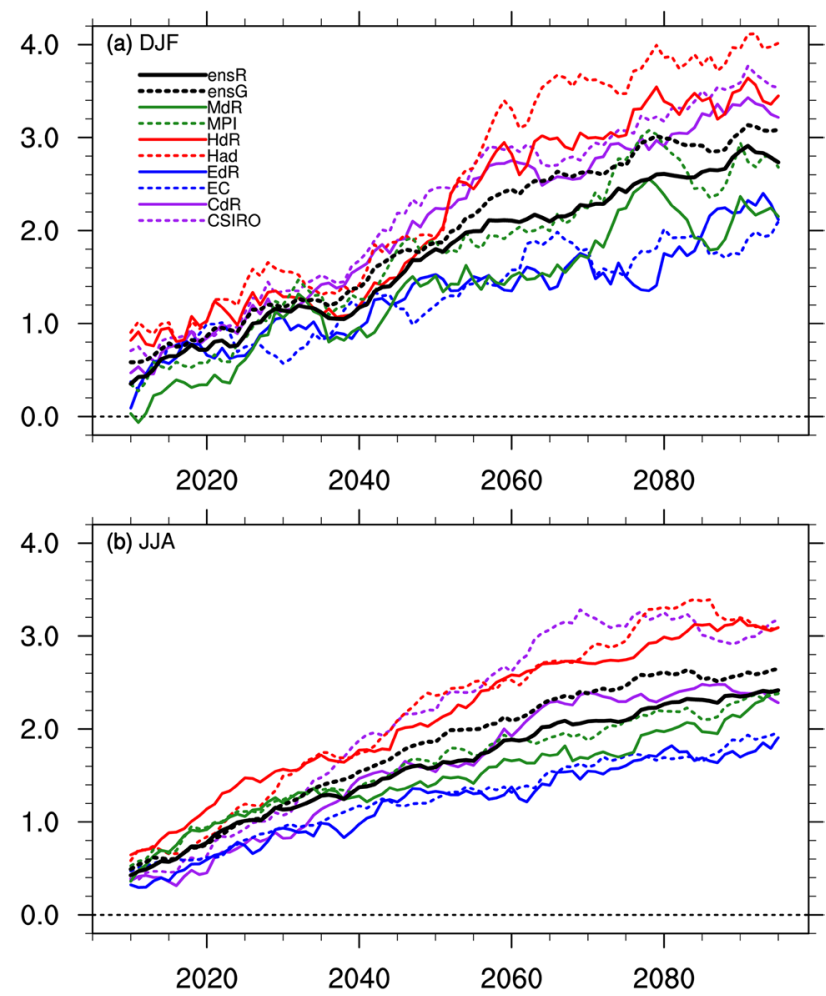

Fig. 10 9-year smoothed time series of temperature changes (unit: ${ }^{\circ}$ C) in DJF (a) and JJA (b) over China during 2006-2099 (relative to 1986-2005). The different colored lines indicate different model simulations
Acknowledgement This research was jointly supported by the National Key Research and Development Program of China (2018YFB1502803), the Strategic Priority Research Program of the Chinese Academy of Sciences (Grant No. XDA20060401), the Science and Technology Program of Yunnan "Impact assessments and monitor-forecasting technology of meteorological disasters for Yunnan plateau characteristic agriculture under climate change" (Grant No. 2018BC007), and National Natural Science Foundation of China (41805074, 41375104).

Open Access This article is distributed under the terms of the Creative Commons Attribution 4.0 International License (http://creativeco mmons.org/licenses/by/4.0/), which permits unrestricted use, distribution, and reproduction in any medium, provided you give appropriate credit to the original author(s) and the source, provide a link to the Creative Commons license, and indicate if changes were made.

\section{References}

Boberg F, Christensenc JH (2012) Overestimation of Mediterranean summer temperature projections due to model deficiencies. Nat Clim Change 2:433-436. https://doi.org/10.1038/nclimate1454

Chen N, Gao XJ (2019) Climate change in the 21st century over China: The projections by a RCM and the driving GCM. Atmos Ocean Sci Lett (accepted)

Christensen JH, Boberg F (2013) Temperature dependent climate projection deficiencies in CMIP5 models. Geophys Res Lett 39:L24705

Christensen JH, Hewitson B, Busuioc A et al (2007) Regional climate projections. In: Solomon S, Qin D, Manning M et al (eds) Climate change 2007: the physical science basis. Contribution of Working Group I to the 4th assessment report of the Intergovernmental Panel on Climate Change. Cambridge University Press, Cambridge, pp 847-940

Collins WJ, Bellouin N, Doutriaux-Boucher M et al (2011) Development and evaluation of an Earth-System model-HadGEM2. Geosci Model Dev 4:1051-1075

de Elia R, Cote H (2010) Climate and climate change sensitivity to model configuration in the Canadian RCM over North America. Meteorol Z 19:325-339

Déqué M, Jones RG, Wild M, Giorgi F (2005) Global high resolution versus limited area model climate change projections over Europe: quantifying confidence level from PRUDENCE results. Clim Dyn 25:653-670

Déqué M, Somot S, Sanchez-Gomez E, Goodess CM, Jacob D, Lenderink G, Christensen OB (2012) The spread amongst ENSEMBLES regional scenarios: regional climate models, driving general circulation models and interannual variability. Clim Dyn 38(5-6):951-964

Di Luca A, Elía R, Laprise R (2012) Potential for small scale added value of RCM's downscaled climate change signal. Clim Dyn 40:601-618

Diaconescu EP, Laprise R (2013) Can added value be expected in RCM simulated large scales? Clim Dyn 41:1769-1800

Eum H, Gachon P, Laprise R (2015) Impacts of Model Bias on the Climate Change Signal and Effects of Weighted Ensembles of Regional Climate Model Simulations: a Case Study over Southern Québec, Canada. Adv Meteorol 1478514:1-17. https://doi. org/10.1155/2016/1478514

Flato G, Marotzke J, Abiodun B et al (2013) Evaluation of climate models Climate Change 2013: the physical science basis. Contribution of Working Group I to the Fifth Assessment Report of the 
Intergovernmental Panel on Climate Change. Cambridge University Press, Cambridge, pp 741-866

Gao XJ, Giorgi F (2017) Use of the RegCM system over East Asia: review and perspectives. Engineering 3(5):766-772

Gao XJ, Zhao ZC, Ding YH, Huang RH, Giorgi F (2001) Climate change due to greenhouse e_ects in China as simulated by a regional climate model. Adv Atmos Sci 18:1224-1230

Gao XJ, Xu Y, Zhao ZC, Pal JS, Giorgi F (2006) On the role of resolution and topography in the simulation of East Asia precipitation. Theor Appl Climatol 86:173-185

Gao XJ, Shi Y, Song RY, Giorgi F, Wang YG, Zhang DF (2008) Reduction of future monsoon precipitation over China: comparison between a high resolution RCM simulation and the driving GCM. Meteorol Atmos Phys 100:73-86

Gao XJ, Shi Y, Zhang DF, Wu J, Giorgi F, Ji ZM, Wang YG (2012) Uncertainties of monsoon precipitation projection over China: results from two high resolution RCM simulations. Clim Res 52:213-226

Gao XJ, Shi Y, Giorgi F (2016) Comparison of convective parameterizations in RegCM4 experiments over China with CLM as the land surface model. Atmos Ocean Sci Lett 9:246-254

Gao XJ, Shi Y, Han ZY, Wang ML, Wu J, Zhang DF, Xu Y, Giorgi F (2017) Performance of RegCM4 over major river basins in China. Adv Atmos Sci 34:441-455. https://doi.org/10.1007/ s00376-016-6179-7

Gao XJ, Wu J, Shi Y, Wu J, Han ZY, Zhang DF, Tong Y, Li RK, Xu Y, Giorgi F (2018) Future changes in thermal comfort conditions over China based on multi-RegCM4 simulations. Atmos Oceanic Sci Lett 11(4):291-299

Giorgi F (2008) A simple equation for regional climate change and associated uncertainties. J Clim 21:1589-1604

Giorgi F, Coppola E (2010) Does the model regional bias affect the projected regional climate change? An analysis of global model projections. Clim Change 100:787-795

Giorgi F, Hurrell JW, Marinucci MR, Beniston M (1997) Elevation dependency of the surface climate change signal: a model study. J Clim 10:288-296

Giorgi F, Whetton PH, Jones RG, Christensen JH, Mearns LO, Hewitson B, vonStorch H, Francisco R, Jack C (2001) Emerging patterns of simulated regional climatic changes for the 21 st century due to anthropogenic forcings. Geophys Res Lett 28:3317-3320

Giorgi F, Jones C, Asrar G (2009) Addressing climate information needs at the regional level: the CORDEX framework. WMO Bull 58:175-183

Giorgi F, Coppola E, Solmon F, Mariotti L (2012) RegCM4: model description and illustrative basic performance over selected CORDEX domains. Clim Res 52:7-29

Han Z, Gao XJ, Shi Y, Wu J, Wang ML, Giorgi F (2015) Development of Chinese high resolution land cover for the RegCM4/CLM and its impact on regional climate simulation. J Glaciol Geocryol 37:857-866 (in Chinese)

Han ZY, Zhou BT, Xu Y, Wu J, Shi Y (2017) Projected changes in haze pollution potential in China: an ensemble of regional climate model simulations. Atmos Chem Phys 17:10109-10123. https:// doi.org/10.5194/acp-17-10109-2017

Hazeleger W, Severijns C, Semmler T et al (2010) EC-Earth: a seamless earth-system prediction approach in action. Bull Am Meteorol Soc 91:1357-1363

Hirakuchi H, Giorgi F (1995) Multi-year present day and $2 \times \mathrm{CO}_{2}$ simulations of monsoon-dominated climate over eastern Asia and Japan with a regional climate model nested in a general circulation model. J Geophys Res 100:21105-21126

Holtslag AAM, De Bruijn EIF, Pan HL (1990) A high resolution air mass transformation model for short-range weather forecasting. Mon Weather Rev 118:1561-1575
Hui PH, Tang JP, Wang SY, Niu XR, Zong PS, Dong XN (2018) Climate change projections over China using regional climate models forced by two CMIP5 global models. Part I: evaluation of historical simulations. Int J Climatol 38(51):e57-e77

Jacob D, Petersen J, Eggert B et al (2014) EURO-CORDEX: new high-resolution climate change projections for European impact research. Reg Environ Change 14:563-578

Jiang DB, Tian ZP, Liang XM (2016) Reliability of climate models for China through the IPCC Third to Fifth Assessment Reports. Int J Climatol 36:1114-1133

Jungclaus JH, Fischer H, Haak H et al (2013) Characteristics of the ocean simulations in MPIOM, the ocean componentof the MPIearth system model. J Adv Model Earth Syst 5(2):422-446

Kang IS, Yoo JH (2006) Examination of multi-model ensemble seasonal prediction methods using a simple climate system. Clim Dyn 26:285-294

Kiehl J, Hack J, Bonan G, Boville B, Williamson D, Rasch P (1998) The National Center for Atmospheric Research Community Climate Model: CCM3. J Clim 11:1131-1149

Kirtman B, Power SB, Adedoyin JA et al (2013) Near-term climate change: projections and predictability. Climate Change 2013: the physical science basis. Contribution of Working Group I to the Fifth Assessment Report of the Intergovernmental Panel on Climate Change. Cambridge University Press, Cambridge, pp 953-1028

Lee J, Hong S (2014) Potential for added value to downscaled climate extremes over Korea by increased resolution of a regional climate model. Theor Appl Climatol 117:667-677

Mearns LO, Sain S, Leung LR et al (2013) Climate change projections of the North American regional climate change assessment program (NARCCAP). Clim Change 120(4):965-975

MWRC (The Ministry of Water Resources of China) (1981) Preliminary assessments of water resources in China. The Ministry of Water Resources of China, Beijing (in Chinese)

Myhre GD, Shindell FM, Bréon W et al (2013) Anthropogenic and natural radiative forcing. Climate Change 2013: the physical science basis. Contribution of Working Group I to the Fifth Assessment Report of the Intergovernmental Panel on Climate Change. Cambridge University Press, Cambridge, pp 659-740

Niu XR, Wang SY, Tang JP et al (2015) Projection of Indian summer monsoon climate in 2041-2060 by multiregional and global climate models. J Geophys Res Atmos 120(5):1776-1793

Oleson K, Niu GY, Yang ZL, Lawrence D, Thornton P, Lawrence P, Stöckli R, Dickinson R, Bonan G, Levis S (2008) Improvements to the Community Land Model and their impact on the hydrological cycle. J Geophys Res 113:G01021. https://doi.org/10.1029/2007J G000563

Olson R, Evans JP, Di Luca A, Argueso D (2016) The NARCliM project: model agreement and significance of climate projections. Clim Res 69:209-227

Pal JS, Small EE, Eltahir EAB (2000) Simulation of regionalscale water and energy budgets: representation of subgrid cloud and precipitation processes within RegCM. J Geophys Res 105:29579-29594

Park C, Min S-K, Lee D et al (2016) Evaluation of multiple regional climate models for summer climate extremes over East Asia. Clim Dyn 46:2469-2486

Rotstayn LD, Collier MA, Dix MR et al (2010) Improved simulation of Australian climate and ENSO-related rainfall variability in a global climate model with an interactive aerosol treatment. Int J Climatol 30:1067-1088

Rummukainen M (2016) Added value in regional climate modeling. Wiley Interdiscip Rev Clim Chang 7:145-159

Shi Y, Wang GL, Gao XJ (2017) Role of resolution in regional climate change projections over China. Clim Dyn 51:2375-2396 
Sørland SL, Schar C, Luthi D, Kjellstrom K (2018) Bias patterns and climate change signals in GCM-RCM model chains. Environ Res Lett 13:074017

Stevens B, Giorgetta M, Esch M et al (2012) The atmospheric component of the MPI-M earth system model: ECHAM6. J Adv Model Earth Syst 5:146-172

Tamara J, McGrath F, Macadam I, Jones R (2019) High-resolution climate projections for South Asia to inform climate impacts and adaptation studies in the Ganges-Brahmaputra-Meghna and Mahanadi deltas. Sci Total Environ 650:1499-1520. https://doi. org/10.1016/j.scitotenv.2018.08.376

Tang JP, Li Q, Wang SY et al (2016) Building Asian climate change scenario by multi-regional climate models ensemble. Part I: surface air temperature. Int J Climatol 36(13):4241-4252

Tang JP, Wang SY, Niu XR, Hui PH, Zong PS, Wang XY (2017) Impact of spectral nudging on regional climate simulation over CORDEX East Asia using WRF. Clim Dyn 48:2339-2357

Tebaldi C, Knutti R (2007) The use of the multi-model ensemble in probabilistic climate projections. Philos Trans R Soc Lond A 365:2053-2075

Tiedtke M (1989) A comprehensive mass flux scheme for cumulus parameterization in large-scale model. Mon Weather Rev 117(8):1779-1800

van Oldenborgh GJ, Drijfhout S, van Ulden A, Haarsma R, Sterl A, Severijns C, Hazeleger W, Dijkstra H (2009) Western Europe is warming much faster than expected. Clim Past 5:1-12

Woldemeskel FM, Sharma A, Sivakumar B, Mehrotra R (2015) Quantification of precipitation and temperature uncertainties simulated by CMIP3 and CMIP5 models. J Geophys Res Atmos 121:3-17. https://doi.org/10.1002/2015JD023719
Wu J, Gao XJ (2013) A gridded daily observation dataset over China region and comparison with the other datasets. Chin J Geophys 56:1102-1111 (in Chinese)

Wu J, Gao XJ, Xu Y (2018) Climate change projection over Xiong'an District and its adjacent areas: an ensemble of RegCM4 simulations. Chin J Atmos Sci 42(3):696-705 (in Chinese)

$\mathrm{Xu} \mathrm{Y,} \mathrm{Gao} \mathrm{XJ,} \mathrm{Giorgi} \mathrm{F} \mathrm{(2010)} \mathrm{Upgrades} \mathrm{to} \mathrm{the} \mathrm{REA} \mathrm{method} \mathrm{for}$ producing probabilistic climate change predictions. Clim Res 41:61-81

Yu ET, Wang HJ, Sun JQ (2010) A quick report on a dynamical downscaling simulation over China using the nested model. Atmos Oceanic Sci Lett 3:325-329

Yu ET, Sun JQ, Chen HP, Xiang WL (2015) Evaluation of a high-resolution historical simulation over China: climatology and extremes. Clim Dyn 45:2013-2031

Zhou TJ, Li ZX (2002) Simulation of the East Asian summer monsoon by using a variable resolution atmospheric GCM. Clim Dyn 19:167-180

Zou LW, Zhou TJ (2013) Near future (2016-2040) summer precipitation changes over China as projected by a regional climate model (RCM) under the RCP8.5 emissions scenario: comparison between RCM downscaling and the driving GCM. Adv Atmos Sci 30:806-818

Zwiers FW, von Storch H (1995) Taking serial correlation into account in tests of the mean. J Climate 8:336-351

Publisher's Note Springer Nature remains neutral with regard to jurisdictional claims in published maps and institutional affiliations. 